1 Instituto Federal de Santa Catarina (IFSC), Departamento de Enfermagem - Joinville (SC), Brasil.

luciana.mazon@ifsc.edu.br

2 Universidade Federal de Santa Catarina (UFSC),

Departamento de Saúde Pública - Florianópolis

(SC), Brasil.

claudia.colussi@ufsc.br

3 Universidade do

Contestado (UNC)

Departamento de

Administração - Mafra

(SC), Brasil.

senff@unc.br

4 Universidade Federal de Santa Catarina, Programa de Pós-Graduação em Saúde Coletiva -

Florianópolis (SC), Brasil.

sergio.freitas@ufsc.br

\section{Execução financeira dos blocos de financiamento da saúde nos municípios de Santa Catarina, Brasil}

\author{
Financial execution of health financing blocks in the municipalities of \\ Santa Catarina, Brazil
}

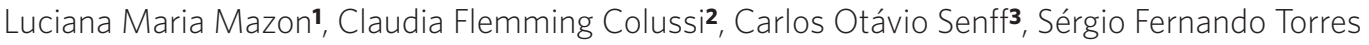
de Freitas 4

RESUMO Foi analisada a utilização dos recursos transferidos de outras instâncias federativas aos blocos de financiamento da saúde pelos municípios de Santa Catarina. Trata-se de um estudo descritivo dos anos de 2009 e 2015. Observou-se que os municípios investem recursos próprios em saúde muito além do recomendado legalmente, no entanto, não conseguem fazer uso integral dos recursos de transferência direta efetuados pelo estado e pela União aos blocos de financiamento da saúde. Nota-se, porém, diminuição expressiva no montante de recurso subutilizado no período analisado, o que sinaliza a melhoria da capacidade de gestão dos recursos de transferência direta.

PALAVRAS-CHAVE Avaliação em saúde. Financiamento público. Investimentos em saúde.

ABSTRACT The use of the resources transferred from other federative instances to health financing blocks by the municipalities of Santa Catarina was analyzed. This is a descriptive study of the years 2009 and 2015. It was observed that municipalities invest their own health resources well beyond what is legally recommended, however, they cannot make full use of the direct transfer resources made by the state and the Union to the blocks of health financing. It is noted, however, a significant reduction in the amount of resources underutilized in the analyzed period, which indicates an improvement in the capacity to manage direct transfer resources.

KEYWORDS Health evaluation. Public financing. Investments. 


\section{Introdução}

A criação do Sistema Único de Saúde (SUS) representou significativo avanço para atender às demandas por saúde no Brasil, no entanto, o financiamento tem se mostrado insuficiente para assegurar recursos adequados e estáveis para a manutenção da estrutura desse sistema ${ }^{1}$. Ocorre que a despesa com saúde tem aumentado em todo o Brasil, em termos nominais, mas o ajuste pela inflação mostra redução líquida ${ }^{\mathbf{1} 2}$. No ano de 2014, o SUS gastou 3,9\% do seu Produto Interno Bruto (PIB) com saúde (União - 1,7\%; estados - $1 \%$; e municípios $-1,2 \%$ ), enquanto a média de gastos públicos de países europeus com sistemas universais, tais como Alemanha, Suécia, Reino Unido, Espanha e França, foi de $8 \%$ no mesmo período ${ }^{3}$.

A ineficiência do gasto público é outro fator que contribui para o subfinanciamento da saúde. Para ilustrar esse cenário, relatório da Organização Mundial da Saúde (OMS) assinala que cerca de 20 a $40 \%$ dos recursos gastos com saúde no mundo são desperdiçados, recursos que poderiam ser redirecionados 4 .

O modelo institucional do SUS foi construído para ser operado de forma tripartite, sendo as transferências intergovernamentais o elemento central no sistema de relação federativa no Brasil e um item fundamental de receita para estados e municípios. O SUS é financiado por meio do orçamento da seguridade social, que engloba saúde, previdência e assistência social, sendo as principais fontes de recursos para a saúde a Contribuição sobre o Lucro Líquido (CSLL) e o Financiamento da Seguridade Social (Cofins), pagas pelas empresas à União 5 .

A União é responsável por aplicar, anualmente, em ações e serviços públicos de saúde, de acordo com Emenda Constitucional $\mathrm{n}^{\circ} 86$, de 17 de março de 2015 , o montante correspondente ao valor da Receita Corrente Líquida (RCL) do respectivo exercício financeiro, de forma escalonada, em cinco anos. A aplicação no primeiro exercício financeiro deve ser de $13,2 \%$, até alcançar $15 \%$ no quinto exercício. A partir de 2018, esse valor passa a ser congelado por 20 anos, podendo ser corrigido apenas pela inflação do ano anterior (Emenda Constitucional 95/2016), medida que limitará de forma austera os recursos à saúde ${ }^{6,7}$.

Já para os estados e municípios, o valor anual aplicado em ações e serviços públicos de saúde deverá ser, respectivamente, no mínimo, de $12 \%$ e $15 \%$ da arrecadação tributária. Com a nova proposta, a tendência será a redução dos gastos com saúde, já que as unidades federativas que ainda não aplicavam o valor mínimo constitucional não poderão despender mais do que já gastavam no ano anterior à aprovação das novas regras.

A descentralização dos recursos do Ministério da Saúde para os outros entes da federação ocorre de modo regular e automático por blocos de financiamento, regulamentada pela Portaria GM/MS ${ }^{\circ}$ 204, de 29 de janeiro de 2007. Esses blocos são constituídos por componentes, conforme as especificidades de suas ações e dos serviços de saúde pactuados. São seis os blocos: Atenção Básica (AB); Atenção de Média e Alta Complexidade Ambulatorial e Hospitalar (MAC); Vigilância em Saúde; Assistência Farmacêutica; Gestão do SUS; e Investimentos na Rede de Serviços de Saúde - este último, incluído pela Portaria $n^{\circ} 837$, de 23 de abril de 2009. Define-se que os recursos referentes a cada bloco de financiamento devam ser aplicados nas ações e nos serviços de saúde relacionados ao próprio bloco 8,9 .

No ano de 2017, foi aprovada pelo Ministério da Saúde a Portaria n ${ }^{0}$ 3.992/2017, que efetivou mudanças no modelo de transferência governamental, excluindo os blocos de financiamento anteriormente descritos. Pactuada entre o Ministério da Saúde, o Conselho Nacional dos Secretários

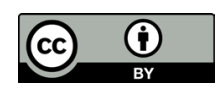

Este é um artigo publicado em acesso aberto (Open Access) sob a licença Creative Commons Attribution, que permite uso, distribuição e reprodução em qualquer meio, sem restrições, desde que o trabalho original seja corretamente citado. 
de Saúde (Conass) e o Conselho Nacional de Secretarias Municipais de Saúde (Conasems), inicialmente como uma estratégia denominada 'SUS Legal', essa mudança visa à reorganização dos planos orçamentários municipais, estaduais e da União, instituindo nova forma de repasse de recursos federais do SUS. Nessa proposta, agora em vigor, capital e custeio passam a ser as duas únicas modalidades de repasse, excluindo-se os seis blocos de financiamento anteriores. A transferência será realizada em conta financeira única, que não permite transferências, e o recurso só poderá ser gasto no que estiver previsto no planejamento da unidade federativa ${ }^{10}$.

Nesse contexto, os municípios têm sido os principais protagonistas dos investimentos em saúde no Brasil. Em 2013, estados, municípios e o Distrito Federal arcaram com $57,41 \%$ dos recursos aplicados em saúde 5 . Em 2016, o percentual médio investido pelos municípios, de acordo com a Ementa Constitucional 29 , foi de $23,8 \%$, muito além dos exigidos $15 \%$.

Escassos recursos e elevada sobrecarga dos municípios com o financiamento da saúde sinalizam a preocupação com o adequado planejamento e o controle na execução do gasto público.

Os deficits orçamentários nas contas públicas brasileiras (reflexo do desequilíbrio nas relações entre as receitas e as despesas) têm sido um problema que reflete em menores índices de eficiência do setor público. Além do deficits orçamentário, outro problema são as limitações na utilização plena dos recursos repassados pela União e pelos estados às instâncias receptoras (municípios), o que torna urgente e necessária a avaliação dos processos de gestão.

O objetivo deste estudo foi analisar a execução financeira dos recursos transferidos por entes federativos aos municípios do estado de Santa Catarina, Brasil, destinados ao financiamento da saúde nos anos de 2009 e 2015.

\section{Métodos}

\section{Desenho do estudo e coleta de dados}

Trata-se de um estudo descritivo em que foram analisados os dados de execução financeira dos blocos de financiamento da saúde (Atenção Básica, Atenção de Média e Alta Complexidade Ambulatorial e Hospitalar, Vigilância em Saúde, Assistência Farmacêutica, Gestão do SUS e Investimentos na Rede de Serviços de Saúde) dos municípios do estado de Santa Catarina, Brasil, nos anos de 2009 e 2015. Os anos de análise corresponderam ao ano de introdução do bloco de Investimentos na Rede de Serviços de Saúde (2009) e ao último ano com dados informados e já consolidados (2015).

Santa Catarina é uma das 27 unidades federativas do Brasil, constituída por 293 municípios, em 2009, e 295, em 2015.

Foram excluídos os municípios com incompletude dos dados em qualquer das variáveis de análise. Para os anos de 2009 e 2015, foram excluídos, respectivamente, 20 e 21 municípios para o bloco de Atenção Básica, 08 e 34 para Média e Alta complexidade, 19 e 59 para Vigilância em Saúde, 256 e 245 para Gestão do SUS, 280 e 75 para o bloco de Investimento na Rede de Serviços de Saúde, e 39 municípios para ambos os anos no bloco de Assistência Farmacêutica.

Os municípios foram classificados de acordo com o porte populacional em três categorias: pequeno porte (municípios com até 10.000 habitantes), médio porte (municípios de 10.001 a 50.000 habitantes) e grande porte (municípios com mais 50.000 habitantes). O ponto de corte dessas categorias leva em conta a característica do estado de possuir um grande número de municípios de pequeno porte, sendo que, em 2015, havia apenas 13 municípios no estado com mais de 100 mil habitantes.

Os dados referentes às receitas englobaram as transferências Fundo a Fundo, dos níveis federal, estadual e de outros 
municípios, e a fase de despesa correspondeu à liquidada. Optou-se por essa fase, pois é nela que se reconhece a dívida como líquida e certa, em que há a obrigação de pagamento.

Os dados foram obtidos do Sistema de Informações sobre Orçamento Público em Saúde (Siops), do Ministério da Saúde. A busca foi realizada selecionando individualmente cada município na aba 'consulta por unidade executora', definindo como pasta a execução financeira por bloco.

As informações contidas no Siops têm natureza declaratória e buscam manter compatibilidade com as informações contábeis, geradas e mantidas pelos estados e municípios. Pela Lei ${ }^{0} 141 / 2012$, o Siops é de preenchimento obrigatório, atribuindo ao gestor declarante a responsabilidade pela fidedignidade dos dados, possibilitando informações essenciais para o monitoramento e a avaliação do padrão de financiamento e gasto em saúde"1.

\section{Análise dos dados}

Inicialmente, foram analisadas as receitas e as despesas com saúde em cada bloco de financiamento para cada município. Foram somados os valores de transferência federal, estadual e de outros municípios em cada bloco de financiamento e subtraídas às despesas liquidadas. O recurso remanescente foi denominado 'saldo de transferências'. Inicialmente, descartou-se a possibilidade de esses recursos estarem empenhados.

Os dados referentes ao ano de 2009 tiveram seus valores atualizados até 2015 pelo Índice Geral de Preços/Disponibilidade Interna (IGP/DI).

A exploração desse banco de dados foi realizada através de planilhas eletrônicas do Microsoft Excel 2007, sendo apresentadas frequências simples.

Para medir a associação entre as variáveis porte populacional e saldo financeiro dos recursos de transferência, utilizou-se o teste Qui-quadrado, com nível de significância de
5\% ( $<<0,05)$. O programa SPSS 18 foi utilizado para as análises estatísticas.

\section{Resultados}

\section{As receitas e despesas em saúde dos municípios catarinenses}

Os recursos federais destinados às ações e aos serviços de saúde são organizados e transferidos na forma de blocos de financiamento. Nos anos de 2009 e 2015, as transferências Fundo a Fundo (federais e estaduais) aos municípios de Santa Catarina foram, respectivamente, ao valor de $\mathrm{R} \$ 1.225 .540 .444,16$ e $R \$ 1.963 .298 .980,01$, distribuídos em seis blocos, o que representa um aumento de $60,2 \%$ no período.

Ao serem analisadas as receitas, observa-se que os municípios investem em saúde com recursos próprios valor superior ao das transferências governamentais, o que tem representado percentual acima dos $15 \%$ estabelecidos pela Ementa Constitucional 29 (EC). De acordo com informações obtidas diretamente do Siops, os municípios catarinenses investiram, em média, 20 e $24 \%$ dos seus recursos próprios em saúde nos anos de 2009 e 2015, respectivamente, já o estado $12,1 \%$ e $12,8 \%$. No caso dos municípios, o percentual alocado em 2015 superou em $60 \%$ o valor recomendado pela EC 29 , já para o estado esse valor foi de $6,6 \%$, o que ilustra o crescimento do gasto orçamentário dos municípios catarinenses.

Na tabela 1, observa-se que, do total de receitas disponíveis em 2009, 48,4\% tratavam-se de recursos transferidos de outras esferas governamentais. Em 2015, esses valores corresponderam a $41 \%$ do total de receitas. O inverso foi observado com relação ao montante de recursos próprios destinados ao setor, os quais equivaleram, em 2009 , a $51,6 \%$ do total de receitas, passando a $59,0 \%$, em 2015 , o que representa um acréscimo de 7,4\%. 
Tabela 1. Dados orçamentários dos municípios de Santa Catarina (em reais), 2009 e 2015

\begin{tabular}{lrrrrrrr}
\hline Período & Município & & \multicolumn{2}{c}{ Receitas (R\$) } & \multicolumn{2}{c}{ Despesas (R\$) } & \multicolumn{2}{c}{ Saldo Financeiro (R\$) } \\
\hline \multirow{2}{*}{ Ano } & $\mathrm{n}$ & Transferência & Recursos Próprios & TOTAL & Liquidadas & Atual & $\begin{array}{r}\text { Atual + Exercício } \\
\text { Anterior } \\
2009\end{array}$ \\
$2009^{*}$ & 293 & 1.225 .540 .444 & 1.305 .993 .905 & 2.531 .534 .349 & 2.203 .680 .432 & 327.853 .917 & 566.861 .344 \\
2015 & 293 & 1.877 .175 .014 & 2.000 .406 .546 & 3.877 .581 .560 & 3.375 .403 .778 & 502.177 .782 & 868.268 .328 \\
\hline
\end{tabular}

Fonte: Elaboração própria, com dados obtidos do Siops.

*Valores atualizados até 2015 pelo IGP/DI.

Nota-se, ainda, que as despesas são inferiores ao montante de receitas disponíveis, gerando saldo financeiro, que, ao ser somado ao saldo existente do exercício anterior, eleva-se expressivamente (tabela 1).

Nos anos de 2009 e 2015, os saldos financeiros foram de $\mathrm{R} \$ 502.177 .782$ e $\mathrm{R} \$$ 77.303.019, respectivamente, sendo que uma parte desse recurso subutilizado é proveniente de transferências governamentais.

Ao serem analisadas as receitas e despesas, individualmente, de cada município de Santa Catarina, verificou-se que uma parte deles se caracterizou por apresentar deficit financeiro elevado (despesa superior à receita), o que seria esperado, frente às demandas por serviços e aos limitados recursos, no entanto, outros municípios investiram recursos próprios muito além do recomendado pela $\mathrm{EC} 29$, mas não utilizaram integralmente os recursos transferidos pelas outras instâncias federativas, resultando em receita superior a despesas.

\section{A execução financeira dos blocos da saúde em Santa Catarina}

Uma análise por blocos de despesas mostra que o maior percentual de recursos se destinou ao bloco de Média e Alta Complexidade Ambulatorial e Hospitalar (MAC), seguido das ações de Atenção Básica. Os recursos referentes a cada bloco de financiamento são aplicados pelos municípios nas ações e nos serviços de saúde relacionados ao próprio bloco (gráfico 1).

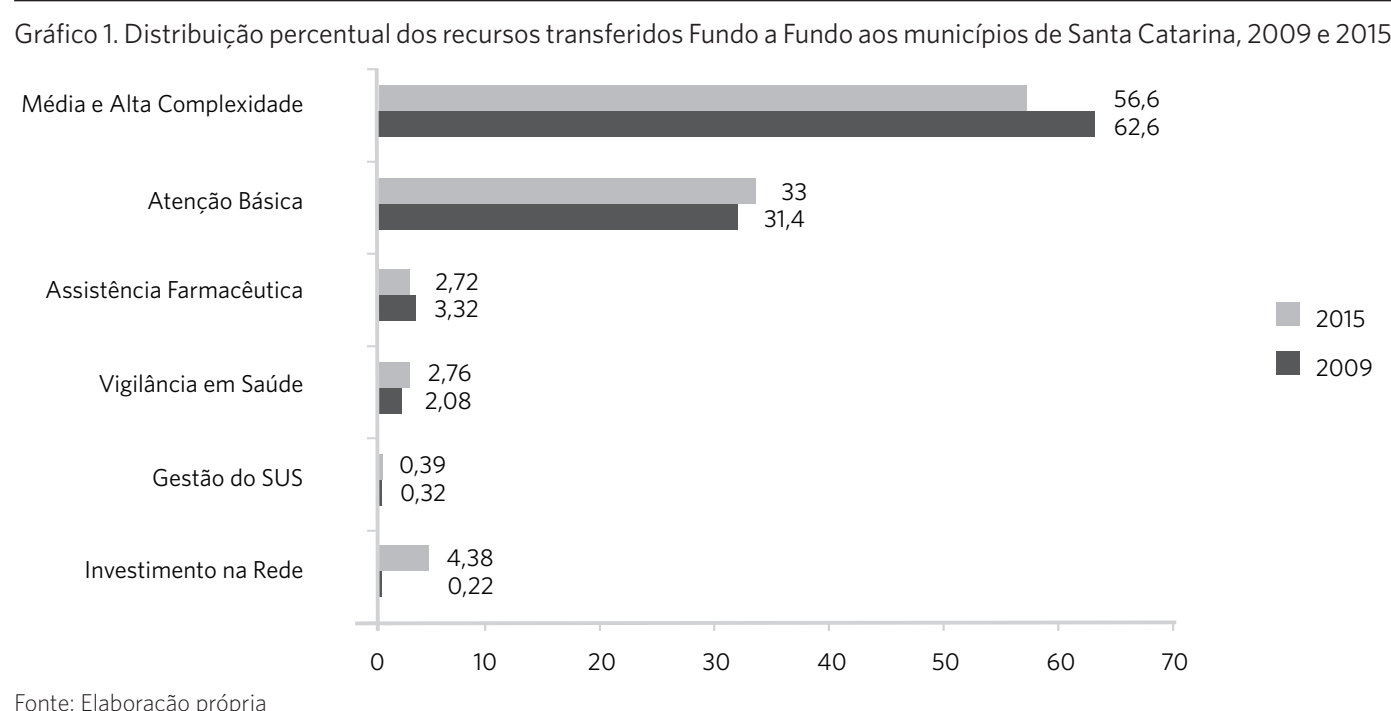


No ano de 2009, o menor percentual subutilizado foi da Atenção Básica, correspondente a $3,1 \%$, sendo que $40(14,6 \%)$ municípios não utilizaram integralmente esse recurso. Os blocos de gestão do SUS e de Investimento na Rede foram os que apresentaram maior saldo, $34,8 \%$ e $65 \%$, respectivamente, mas é importante notar que apenas 13 municípios receberam recursos desses blocos.
Em 2009, 115 municípios deixaram de utilizar integralmente os recursos transferidos ao bloco de Vigilância em Saúde. Comportamento semelhante é evidenciado com os recursos do bloco de Assistência Farmacêutica, em que 15\% do recurso transferido deixaram de ser gastos por 78 municípios (tabela 2).

Tabela 2. Saldo financeiro dos recursos de transferência por bloco de financiamento, Santa Catarina, 2009

\begin{tabular}{|c|c|c|c|c|c|c|}
\hline \multirow{3}{*}{$\begin{array}{l}\text { Ano } \\
\text { Blocos de } \\
\text { Investimento }\end{array}$} & \multicolumn{6}{|c|}{2009} \\
\hline & \multirow{2}{*}{$\begin{array}{r}\text { Municípios } \\
\text { avaliados } \\
n\end{array}$} & \multicolumn{3}{|c|}{ Transferências ( $R \$$ ) } & \multicolumn{2}{|c|}{ Municípios com saldo } \\
\hline & & Transferências ${ }^{\star}$ & 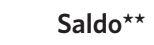 & $\%^{\star \star \star}$ & $\mathrm{n}$ & $\%$ \\
\hline Atenção Básica & 273 & 530.512 .943 & 16.587 .483 & 3,1 & 40 & 14,6 \\
\hline MAC & 285 & 1.103 .059 .905 & 112.857 .877 & 10,2 & 31 & 10,9 \\
\hline Vigilância & 274 & 35.627 .023 & 6.138.617 & 17,2 & 115 & 41,9 \\
\hline Farmacêutica & 254 & 54.087 .461 & 8.334 .988 & 15,4 & 78 & 30,7 \\
\hline Gestão & 37 & 5.664 .585 & 1.971 .310 & 34,8 & 22 & 59,4 \\
\hline Investimento & 13 & 3.922 .377 & 2.547 .730 & 65,0 & 11 & 84,6 \\
\hline
\end{tabular}

Fonte: Elaboração própria, com dados obtidos do Siops.

*Valor ajustado até 2015 pelo índice do IGP/DI.

${ }^{* \star}$ Corresponde aos saldos dos valores transferidos pelas outras instâncias federativas (valores de transferências menos despesas liquidadas).

***Percentual do saldo financeiro com relação ao total transferido.

Observou-se diminuição expressiva no montante de recurso subutilizado do primeiro para o último ano de análise.

No ano de 2015, o saldo dos recursos de transferência do Bloco de Atenção Básica caiu de $3,1 \%$ para $2,4 \%$. Para o MAC, o percentual passou de $10,2 \%$ para $4,2 \%$, já o número de municípios se elevou de 31 para 101.

O bloco de Vigilância em Saúde reduziu o saldo dos recursos de transferência de $17,2 \%$, em 2009, para 5,1\%, em 2015. Para o Bloco de Assistência Farmacêutica, os percentuais passaram de 15,4 para 3,4 (tabela 3). 
Tabela 3. Saldo financeiro dos recursos de transferência por bloco de financiamento, Santa Catarina, 2015

\begin{tabular}{|c|c|c|c|c|c|c|}
\hline \multirow{3}{*}{$\begin{array}{l}\text { Ano } \\
\text { Blocos de } \\
\text { Investimento }\end{array}$} & \multicolumn{6}{|c|}{2015} \\
\hline & \multirow{2}{*}{$\begin{array}{r}\text { Municípios } \\
\text { avaliados } \\
n\end{array}$} & \multicolumn{3}{|c|}{ Transferências (R\$) } & \multicolumn{2}{|c|}{ Municípios com saldo } \\
\hline & & Transferências & Saldo* & $\%^{\star \star}$ & $\mathrm{n}$ & $\%$ \\
\hline Atenção Básica & 274 & 588.577 .625 & 14.350 .115 & 2,4 & 42 & 15,3 \\
\hline MAC & 261 & 1.027 .218 .593 & 43.449 .152 & $4,2 \%$ & 101 & 38,7 \\
\hline Vigilância & 236 & 42.049 .957 & 2.128 .227 & $5,1 \%$ & 79 & 33,5 \\
\hline Farmacêutica & 256 & 45.065 .447 & 1.527 .186 & $3,4 \%$ & 75 & 29,3 \\
\hline Gestão & 50 & 5.480 .774 & 785.852 & $14,3 \%$ & 16 & 32 \\
\hline Investimento & 220 & 54.199 .527 & 24.218 .914 & $44,7 \%$ & 84 & 38,2 \\
\hline
\end{tabular}

Fonte: Elaboração própria, com dados obtidos do Siops

${ }^{*}$ Corresponde aos saldos dos valores transferidos pelas outras instâncias federativas (valores de transferências menos despesas liquidadas).

**Percentual do saldo com relação ao total transferido.

\section{A execução financeira dos recur- sos da saúde e sua relação com o porte populacional dos municípios catarinenses}

Quanto à capacidade de gastos dos recursos de transferência pelos municípios, de acordo com os estratos populacionais, identificou-se que, no ano de 2009, para a Atenção Básica, 27 municípios de pequeno, 09 de médio e 04 de grande porte deixaram de utilizar integralmente os recursos transferidos. Para o bloco MAC, 16 municípios eram de médio e 09 de grande porte, o que representa, proporcionalmente, $51,6 \%$ e $29 \%$, respectivamente. O maior número de municípios nesse estrato pode ser justificado por serem transferidos a estes grupos os maiores volumes de recursos nessa modalidade. Seguem esse critério, também, os blocos de Gestão e Investimentos na rede. Portanto, para estes dois blocos, o maior percentual de municípios foi de grande e médio porte. Para o bloco de Vigilância em Saúde, o maior percentual (55,7\%) foi de municípios de pequeno porte. Similaridade se observa para o bloco de Assistência Farmacêutica, em que $52,6 \%$ foram de municípios de pequeno porte.

$\mathrm{Na}$ análise bivariada para o ano de 2009, foram encontradas associações significativas entre porte populacional e saldo financeiro dos recursos de transferência para os blocos de Média e Alta Complexidade, Gestão do SUS e Investimento na Rede (tabela 4). 
Tabela 4. Municípios catarinenses com saldo financeiro do recurso de transferência, segundo estratos de porte populacional (pequeno, médio e grande), 2009 e 2015

\begin{tabular}{|c|c|c|c|c|c|c|c|c|c|c|c|}
\hline \multirow{2}{*}{$\begin{array}{l}\text { Ano } \\
\text { Blocos de financiamento }\end{array}$} & \multicolumn{6}{|c|}{2009} & \multicolumn{5}{|c|}{2015} \\
\hline & $\mathrm{C} /$ saldo & Grande & Médio & Pequeno & Total & $p^{\star}$ & Grande & Médio & Pequeno & Total & $p^{\prime}$ \\
\hline \multirow[t]{2}{*}{ Atenção Básica } & $\mathrm{n}$ & 04 & 09 & 27 & 40 & 0,477 & 02 & 13 & 27 & 42 & 0,366 \\
\hline & $\%$ & 10 & 22,5 & 67,5 & 100 & & 4,8 & 30,9 & 64,3 & 100 & \\
\hline \multirow[t]{2}{*}{ Média e Alta Complexidade } & $\mathrm{n}$ & 09 & 16 & 06 & 31 & $0,000^{* *}$ & 05 & 39 & 57 & 101 & 0,053 \\
\hline & $\%$ & 29 & 51,6 & 19,4 & 100 & & 05 & 38,6 & 56,4 & 100 & \\
\hline \multirow[t]{2}{*}{ Vigilância em saúde } & $\mathrm{n}$ & 10 & 41 & 64 & 115 & 0,741 & 05 & 22 & 52 & 79 & 0,15 \\
\hline & $\%$ & 8,7 & 35,6 & 55,7 & 100 & & 6,3 & 27,9 & 65,8 & 100 & \\
\hline \multirow[t]{2}{*}{ Assistência farmacêutica } & $\mathrm{n}$ & 10 & 27 & 41 & 78 & 0,413 & 04 & 26 & 45 & 75 & 0,38 \\
\hline & $\%$ & 12,8 & 34,6 & 52,6 & 100 & & 5,3 & 34,7 & 60 & 100 & \\
\hline \multirow[t]{2}{*}{ Gestão } & $\mathrm{n}$ & 11 & 05 & 06 & 22 & $0,000^{* *}$ & 04 & 06 & 06 & 16 & 0,065 \\
\hline & $\%$ & 50 & 22,7 & 27,3 & 100 & & 25 & 37,5 & 37,5 & 100 & \\
\hline \multirow[t]{2}{*}{ Investimento } & $\mathrm{n}$ & 04 & 05 & 02 & 11 & $0,002^{* *}$ & 11 & 32 & 41 & 84 & 0,045 \\
\hline & $\%$ & 36,4 & 45,4 & 18,2 & 100 & & 13,1 & 38,1 & 48,8 & 100 & \\
\hline
\end{tabular}

Fonte: Elaboração própria.

Pequeno porte $=$ até 10 mil habitantes; médio porte $=10.001$ a 50.000 habitantes; grande porte $=$ mais 50 mil habitantes.

${ }^{*} \mathrm{p}=$ valor do teste de Qui-Quadrado

** Valores significativos

Para o ano de 2015, o maior saldo de recursos de transferências para os blocos de Atenção Básica, MAC, Vigilância em Saúde, Assistência Farmacêutica e Investimento foi de municípios de pequeno porte. Para os blocos de Gestão do SUS, observam-se valores percentuais similares para os municípios de médio e pequeno porte (37,5\%). Para o ano de 2015, foram observadas associações significativas na análise bivariada apenas para os blocos de Investimentos na Rede e Média e Alta Complexidade.

\section{Discussão}

O problemático financiamento do SUS, em um cenário do capitalismo contemporâneo em crise ${ }^{12}$, deixa aparente a insuficiência de recursos públicos e a ineficiência na sua aplicação para o alcance de um sistema de saúde universal e equitativo'.

Os dados apresentados demonstram que os municípios catarinenses têm assumido grande responsabilidade no financiamento do sistema de saúde. De modo geral, os municípios brasileiros ampliaram de modo expressivo seus gastos no setor, alocando proporção das receitas próprias em níveis superiores aos determinados constitucionalmente ${ }^{\mathbf{1 3}}$. A descentralização das receitas definidas pelo SUS foi acompanhada da desconcentração de encargos bastante expressivos, que incidiram de forma mais acentuada sobre os municípios, fazendo com que se tornassem a unidade da federação que mais contribuiu para o setor em termos proporcionais à sua arrecadação ${ }^{13}$.

Esse crescimento da participação dos gastos de origem municipal no financiamento da saúde é um comportamento observado, também, nos demais municípios e regiões brasileiras. Piola e Barros ${ }^{14}$ apontam, por exemplo, que na região Sul do País, a participação percentual da União, dos estados e municípios no gasto público total saúde, 
no ano de 2006, foi, respectivamente, de $43 \%$, $23,1 \%$ e $33,9 \%$; já para o ano de 2015 , esses valores passaram a ser de $33,8 \%, 28,1 \%$ e $38,1 \%$, o que revela o maior crescimento das alocações para o SUS por parte dos estados e municípios. No caso da União, o gasto em saúde foi mantido praticamente no mesmo percentual. Os autores afirmam que tal característica se explica pelo fato de que a correção do piso para a aplicação da União no SUS tinha como base a variação nominal do PIB dos anos imediatamente anteriores, e a União apenas tratou de cumprir o piso estabelecido em lei14.

As transferências governamentais na forma de blocos de financiamento e a maior concentração de recursos a um bloco, em detrimento a outro, como o observado para o estado de Santa Catarina, remetem ao processo histórico de consolidação da forma de repasse de recursos pela União aos entes federados.

As transferências intergovernamentais de recursos na área da saúde são pauta de debate e reivindicações desde a criação do SUS pelas Leis $\mathrm{n}^{0} 8.080 / 1990$ e $\mathrm{n}^{0} 8.142 / 1990$, quando em sua redação indicavam que os recursos deveriam ser repassados de forma regular e automática aos municípios, obedecendo a alguns critérios, como perfil epidemiológico, demográfico, características da rede de saúde, desempenho do setor, entre outros ${ }^{15}$.

Mendes ${ }^{16}$ retrata a consolidação histórica dos blocos de financiamento da saúde até a atual discussão para um novo mecanismo de transferência de recursos, em andamento no País. Aponta o autor que somente em 1993, com a criação da Norma Operacional Básica (NOB 01/93), que tratou da descentralização da gestão das ações e dos serviços de saúde, é que essa forma de repasse 'global' realmente ocorreu para alguns municípios, enquadrados em gestão plena, responsáveis por assumir completa responsabilidade sobre a gestão da prestação de serviços. No entanto, frente a muitos embates das esferas de governo, cria-se a NOB 01/96, que buscou disciplinar o processo de organização da gestão, definindo, no que tange às transferências intergovernamentais, que elas aconteceriam de forma regular ou eventual, da União para estados, municípios e Distrito Federal, condicionadas à contrapartida desses níveis de governo. É nesse ponto que se criam os incentivos financeiros, que passam a ser utilizados pelo governo federal para repassar recursos, centralizando o financiamento e fragmentando a proposta de repasse global. Esse cenário torna necessário aos municípios administrar inúmeras contas bancárias para controle dos repasses.

$\mathrm{O}$ autor reforça, ainda, que, frente a esse contexto e à necessidade de um novo mecanismo de transferência, com vistas a reduzir a fragmentação, criam-se os blocos de financiamento (Portaria $n^{\circ}$ 204/2007), que, no entanto, ainda de acordo com Mendes ${ }^{16}$, mantiveram a lógica da oferta sem considerar as características epidemiológicas, socioeconômicas e as necessidades de saúde locais.

A partir da análise dos dados, verifica-se que Média e Alta Complexidade respondem pelo maior percentual dos recursos transferidos Fundo a Fundo no conjunto dos blocos de financiamento, com leve redução percentual de sua participação entre 2009 e 2015. Numa análise realizada por Pescuma Junior e Mendes ${ }^{17}$, com dados de todo País, também não foi encontrado aumento dos valores destinados à MAC com relação ao percentual do PIB, no período de 2000 a 2011. O maior gasto nesse bloco não significa priorização com relação aos demais, uma vez que este bloco se destina ao financiamento de procedimentos de alto custo e complexidade tecnológica. Por outro lado, observou-se em Santa Catarina o aumento percentual da participação do bloco da Atenção Básica no período analisado. Esse panorama é semelhante ao encontrado por Santos e Luiz $^{\mathbf{1 8}}$ quando analisaram os mesmos dados para o Brasil, no período de 2007 a 2015, onde o bloco da Atenção Básica foi o único que aumentou sua participação no total de valores repassados nesse período, refletindo 
a política de priorização da Atenção Básica adotada pelo governo federal.

Os achados apresentados pelo estudo sobre a capacidade de utilização pelos municípios dos recursos financeiros recebidos na forma de transferências Fundo a Fundo evidenciaram que os municípios tiveram dificuldade em utilizar integralmente os recursos transferidos a boa parte dos blocos, particularmente, em 2009. É evidente que a subutilização dos recursos dos blocos precisa ser analisada à luz do contexto de subfinanciamento do sistema de saúde e das amarras burocráticas que, muitas vezes, impedem o uso eficiente e oportuno dos recursos disponíveis.

O menor percentual de recursos de transferência subutilizados foi da Atenção Básica, para ambos os anos definidos para a análise. Isso ocorre porque os municípios são os responsáveis diretos por esse nível de atenção, por ser este serviço a base da rede de saúde para aqueles de pequeno porte, que representam o maior número no estado. Além disso, o estado de Santa Catarina tem se destacado pela qualidade de sua Atenção Básica em relação ao restante do País, o que também reflete na eficiência dos gastos.

Em 2009, destaca-se a grande quantidade de municípios que deixaram de utilizar integralmente os recursos transferidos ao bloco de Vigilância em Saúde, indicando alguma dificuldade de planejamento e execução.

Para o bloco de MAC, o percentual de recurso subutilizado passou de $10,2 \%$ para $4,2 \%$, e o número de municípios se elevou de 31 para 101. Essa elevação pode estar associada à ampliação do número de municípios que passaram a receber recurso para esse bloco de financiamento. O mesmo comportamento pode ter ocorrido com os blocos de Investimentos na Rede e na Gestão do SUS.

O maior montante subutilizado esteve concentrado nos blocos de gestão do SUS e Investimento na Rede. O repasse ao primeiro bloco esteve condicionado à adesão pelos municípios ao Pacto pela Saúde, por meio da assinatura do Termo de Compromisso de Gestão, e o segundo bloco à apresentação de projetos, os quais deveriam ser submetidos à Comissão Intergestores Bipartite (CIB), que avaliam sua conformidade com os planos estaduais e municipais. Os projetos aprovados seriam formalizados em portaria do Ministério da Saúde, com valor, período de execução e cronograma de desembolso dos recursos financeiros a serem transferidos. O bloco de Investimentos na rede exige contrapartidas que oneram financeiramente os municípios ${ }^{19}$. Com a crise financeira dos últimos anos e o grande percentual de gastos já assumidos pelos municípios, receber investimento para assumir novas responsabilidades em que o custeio recaia sobre si, em especial, os custos com recursos humanos, provoca um efeito negativo, de modo que os municípios preferem abrir mão dos recursos ou mesmo desistir de manter serviços já instalados, descumprindo acordos firmados.

Cabe apontar, ainda, que o bloco de Investimento foi introduzido no mesmo ano de análise dos dados (2009), na medida em que não se pode descartar repasse tardio dos recursos pela União aos entes, limitando, assim, seu uso em tempo oportuno.

$\mathrm{Na}$ análise empreendida, uma hipótese possível para a subutilização de recursos é a de que os mecanismos estabelecidos até então para o repasse dos recursos pela União limitaram o gestor de fazer seu uso pleno, associada, em grande medida, ao extenuante e contínuo dispêndio de tempo político, administrativo e programático das secretarias de saúde para gerir as 230 (em média) 'caixinhas' de repasse financeiro ${ }^{15}$.

Os gestores de saúde reconhecem e já sinalizaram a dificuldade imposta pelo modelo de repasse de recursos em vigor, que limita sua atuação por não permitir que disponham livremente dos recursos atrelados a cada bloco específico ${ }^{20}$.

Apesar de a possibilidade do remanejamento de recursos entre os blocos de financiamento existir, ele poderia acontecer em 
apenas duas ocasiões: quando, ao término do exercício anual, houvesse eventuais saldos financeiros disponíveis no bloco de Assistência Farmacêutica, estes poderiam ser remanejados para outros blocos, exceto o de Investimento na Rede de Saúde, se atendidos alguns requisitos; a outra possibilidade definida pela Portaria GM/MS n ${ }^{\circ} 1.073 / 2015$ era reprogramar e remanejar os saldos financeiros disponiveis até 31 de dezembro de 2014. Esse remanejamento poderia ser realizado para blocos de financiamento distintos daquele no qual houve saldo financeiro disponível, com excessão dos blocos de Atenção Básica, MAC, Investimento na Rede e Gestão do SUS. Para o remanejamento, fazia-se necessária a elaboração de um plano de aplicação, a ser aprovado pela Comissão Intergestores Regional (CIR) ou pela Comissão Intergestores Bipartite (CIB) ${ }^{\mathbf{1 8}}$.

O Ministério da Saúde anunciou, em 2017, alterações no modelo de repasse dos recursos da União para estados e municípios, por meio da Portaria $n^{0} 3.992 / 2017$. Os repasses, antes realizados em seis blocos temáticos ${ }^{8}$, passam a ser feitos em duas modalidades: custeio e investimento. A medida foi aprovada em reunião da Comissão Intergestores Tripartite (CIT) e apoiada pelo Conass e pelo Conasems, em janeiro de 201721. Essa definição pode apresentar avanços e retrocessos.

Os avanços são de que a nova proposta de repasse federal, delineada para ser unificada, global e regular, é um elo estratégico para qualificação do SUS, dando maior autonomia aos gestores na construção do modelo de saúde, com base em suas necessidades locais, permitindo avanços no processo de regionalização do SUS. Além de eliminar a dificuldade em gerir centenas de 'microrrepasses', que limitam a utilização plena dos recursos, o que resulta em ineficiência ${ }^{15}$. Um possível retrocesso é de que a mudança, sem critérios de rateio bem definidos, poderá desviar recursos de áreas com menor visibilidade, como a Vigilância em Saúde, para áreas como a de média e alta complexidade, permitindo ao setor privado, prestador de serviços, exercer pressão sobre os gestores locais por mais recursos ${ }^{15}$. Autores reiteram que o fundamental em todo esse processo é que não se trata apenas de unificar os blocos. É necessário definir os critérios de rateio que deverão ser construídos 'de baixo para cima' e estar pautados nas necessidades de saúde loco/regionais, medidas por critérios demográficos, epidemiológicos, socioeconômicos e espaciais ${ }^{16,21}$.

Cabe, ainda, mencionar que os dados da pesquisa revelam uma redução significativa no montante de recursos subutilizados de 2009 para 2015. Esse fato pode ser um indicativo de avanço na capacidade de gestão dos recursos, dada a recente implantação dos blocos de financiamento, em 2009.

Com relação à capacidade de gastos dos recursos de transferências por estratos de municípios (grande, médio e pequeno porte), o resultado evidenciou haver associação entre as variáveis para o ano de 2015 apenas para o bloco de Investimentos na Rede e MAC, já para o ano de 2009, houve associação significativa para os blocos de Investimentos, MAC e Gestão do SUS.

Estudo conduzido por Simão e Orellano ${ }^{19}$ evidenciou que a arrecadação municipal é um fator que influencia positivamente o recebimento de transferências Fundo a Fundo do SUS. Os autores comprovaram a hipótese de que municípios que mais arrecadam, por terem mais recursos para a saúde, são os que têm mais incentivos a aderir ou ofertar os programas e serviços que recebem transferência federal através do SUS.

Estudo, como de Machado e Santos Guim $^{22}$, sugerem a hipótese de que municípios de menor porte populacional teriam menor capacidade de adesão a programas federais, percebendo menor volume de transferências condicionadas do SUS. Com isso, menores transferências resultariam em menor volume de recursos a serem gastos, $\mathrm{o}$ que poderia tornar mais fácil utilizá-los. No entanto, nesses municípios, teria-se menor 
agregado de capacidade técnica, consequentemente, menor capacidade de gasto dos recursos transferidos. Já municípios com maior concentração na oferta de serviços de média e alta complexidade assistencial seriam mais populosos, com maior capacidade técnica e tenderiam a captar mais transferências, seguindo, assim, a mesma lógica anteriormente apresentada.

\section{Conclusões}

O conjunto dos achados deste estudo sugere a necessidade de avançar na avaliação da eficiência e do padrão dos gastos públicos em saúde pelos entes federados.

Um instrumento significativo para potencializar a capacidade de avaliação dos serviços pelos gestores municipais é o Siops, uma ferramenta que mantém compatibilidade com as informações contábeis, geradas e mantidas pelos municípios, possibilitando informações essenciais para o monitoramento e a avaliação contínua do padrão de financiamento e gasto em saúde.

Por fim, reitera-se que a análise empreendida neste estudo enfatiza a importância do processo de racionalização dos recursos, que não pode ser confundido com racionamento de despesas, como já descrito por Hartz e Pouvorville23, devendo ser um forte argumento contra o subfinanciamento do setor.

\section{Colaboradores}

Todos os autores contribuíram significativamente para todas as etapas de produção do manuscrito, revisão crítica do conteúdo e aprovação de sua versão final.

\section{Agradecimentos}

Ao Programa Uniedu/Fumdes pela concessão de bolsa de estudo de doutoramento. 


\section{Referências}

1. Paim J, Travassos C, Almeida C, et al. The Brazilian health system: history, advances, and challenges. Lancet. 2011 May 21; 377(9779):1778-1797.

2. Marques RM, Mendes A. A problemática do financiamento da saúde pública brasileira: de 1985 a 2008. Econ. Soc. [internet] 2012 Ago [acesso em 2017 jul 20]; 21(2):345-362. Disponível em: http://www.scielo.br/scielo.php?script $=$ sci $_{-}$ arttext\&pid=S0104-06182012000200005\&lng=en\& nrm=iso.

3. Mendes A, Funcia FR. O SUS e seu financiamento. In: Marques R, Piola SF, Roa AC. Sistema de Saúde no Brasil: organização e financiamento. Rio de Janeiro: Abres; Brasilia, DF: Ministério da Saúdel; 2016. p. 139-168.

4. Organização Mundial da Saúde. Financiamento do sistema de saúde: o caminho para a cobertura universal. Geneva: OMS; 2010 [acesso em $2017 \mathrm{fev}$ 6]. Disponível em: http://www.who.int/whr/2010/ whr10_pt.pdf.

5. Conselho Nacional de Secretários de Saúde. A Gestão do SUS. Brasília, DF: Conass; 2015.

6. Brasil. Constituição 1988. Emenda Constitucional 86, de 17 de março de 2015. Altera os arts. 165, 166 e 198 da Constituição Federal, para tornar obrigatória a execução da programação orçamentária que especifica. Lex: legislação federal e marginalia. 2015.

7. Brasil. Constituição 1988. Emenda Constitucional 95, de 15 de novembro de 2016. Altera o Ato das Disposições Constitucionais Transitórias, para instituir o Novo Regime Fiscal, e dá outras providências. Lex: legislação federal e marginalia. 2016.

8. Brasil. Ministéio da Saúde. Portaria GM/MS n 204, de 29 de janeiro de 2007. Regulamenta o financiamento e a transferência dos recursos federais para as ações e os serviços de saúde, na forma de blocos de financiamento, com o respectivo monitoramento e controle. Diário oficial da União. Jan 2007.
9. Brasil. Portaria n ${ }^{\circ} 837$, de 23 de abril de 2009. Altera e acrescenta dispositivos à Portaria no 204/GM, de 29 de janeiro de 2007. Diário oficial da União. Abr 2009.

10. Brasil. Conselho Nacional de Secretarias Municipais de Saúde. SUS Legal: Conasems, Conass e Ministério pactuam novo modelo de repasse de recursos do SUS [internet]. Brasília, DF: Conasems; 2017 [acesso em 2017 mar 7]. Disponível em: http:// www.conasems.org.br/sus-legal-conasems-conass-e-ministerio-pactuam-novo-modelo-de-repasse-do-sus.

11. Brasil. Lei no 141, de 13 de janeiro de 2012. Regulamenta o 9 3o do art. 198 da Constituição Federal. Diário oficial da União. 14 de jan 2012.

12. Mendes A. Brazilian public health in the context of a State crisis or a crisis of capitalism? Saude soc. [internet]. 2015 Jun [acesso em 2017 abr 12]; 24(1):6681. Disponível em: http://www.scielo.br/scielo. php?script=sci_arttext\&pid=S01042902015000500 066\&lng $=\mathrm{en}$.

13. Araujo CEL, Gonçalves GQ, Machado JA. Os municípios brasileiros e os gastos próprios com saúde: algumas associações. Ciênc Saúde Colet [internet]. 2017 Mar [acesso 2017 ago 15]; 22(3):953-963. Disponível em: http://www.scielo.br/scielo.php?script=sci_arttext\&pid=S1413$-81232017002300953 \& \operatorname{lng}=$ en.

14. Piola SF, Barros MED. O financiamento dos serviços de saúde no Brasil. In: Marques R, Piola SF, Roa AC. Sistema de Saúde no Brasil: organização e financiamento. Rio de Janeiro: Abres; Brasília, DF: Ministério da Saúde; 2016. p. 101-138.

15. Santos NR. O repasse federal unificado do Ministério da Saúde para Estados e Municípios: considerações para um posicionamento e mobilização. Ensaios Diál [internet]. 2016 Nov [acesso em 2017 jun]; 3:32-33. 
16. Fundação Oswaldo Cruz. Escola Politécnica de Saúde Joaquim Venâncio. Entrevista: Áquilas Mentes [internet]. $2017 \mathrm{Fev} 17$ [acesso em 2017 jul 9]. Disponível em: http://www.epsjv.fiocruz.br/noticias/entrevista/o-grande-problema-e-a-falta-de-dinheiro-para-o-sus-e-nao-a-forma-de-repasse.

17. Pescunar Junior A, Mendes A. O Fundo Nacional de Saúde e a Prioridade da Média e Alta Complexidade. Argumentum [internet]. 2015 Jul-Dez [acesso em 2017 jan 18]; 7(2):161-177. Disponível em: http:// www.portaldepublicacoes.ufes.br/argumentum/ article/view/10510.

18. Santos RJM, Luiz VR. Transferências federais no financiamento da descentralização. In: Marques R, Piola SF, Roa AC. Sistema de Saúde no Brasil: organização e financiamento. Rio de Janeiro: Abres; Brasília, DF: Ministério da Saúde; 2016. p. 169-204.

19. Simão JB, Orellano VIF. Um estudo sobre a distribuição das transferências para o setor de saúde no Brasil. Estud. Econ. [internet]. 2015 Mar. [acesso em 2017 jun 22]; 45(1):33-63. Disponível em: http://www.scielo.br/scielo.php?script=sci arttext\&pid=S0101-41612015000100033\&lng=en\&n $\mathrm{rm}=\mathrm{iso}$.

20. Brasil. Governo do Brasil. Gestores implementam lei que otimiza repasses para a saúde [internet]. [Brasília, DF]: Portal Brasil; 2017 [acesso em 2017 mar 2]. Disponível em: http://www.brasil.gov.br/ saude/2017/02/gestores-implementam-lei-que-otimiza-repasses-para-a-saude.

21. Juqueira MG. Sistema único de saúde - Caixa Único. Ensaios Diál [internet]. 2016 Nov [acesso em 2017 jun 10]; 3:34-35. Disponível em: https://www. abrasco.org.br/site/wp-content/uploads/2017/03/ artigo_MAURO_JUNQUEIRA_PDF_marco_2017. pdf.

22. Machado JA, Santos Guim AL. Gestão e poder local. Descentralização e igualdade no acesso aos serviços de saúde: o caso do Brasil. Rev. Serv. Público [internet]. 2017 Jan-Mar. [acesso em 2017 ago 20]; 68(1):37-64. Disponível em: http://repositorio.enap. gov.br/bitstream/1/2948/1/RSP\%20V.68\%20N.1_ artigo\%20de\%2037-64.pdf.

23. Hartz ZMA, Pouvourville G. Avaliação dos Programas de Saúde: a eficiência em questão. Ciênc Saúde Colet. [internet]. 1998 Jun [acesso em 2017 fev 8]; 3(1):68-82. Disponível em: http://www. scielo.br/scielo.php?script=sci_arttext\&pid=S1413$-81231998000100068 \& \operatorname{lng}=\mathrm{en}$.

Recebido em 02/10/2017

Aprovado em 03/02/2018

Conflito de interesses: inexistente

Suporte financeiro: não houve 